\title{
Research on the Mode of Cultivating Innovative Talents in Clothing and Apparel Design Specialty
}

\author{
Mingjun Gao ${ }^{1, a}$ \\ ${ }^{1}$ Fine Arts Academy of Northeast Normal University, Changchun City, Jilin Province, China, 130000 \\ a 476188851@qq.com
}

Keywords: Clothing and apparel design specialty; Talent training; Innovative talents; Training mode

\begin{abstract}
Many colleges in China are setting up clothing and apparel design specialty, but viewing this specialty talent training mode we can find that there are some very obvious problems in the cultivation of innovative talents. This article focuses on the analysis of the existing problems, and puts forward the corresponding recommendations. We hope that China's universities can be in accordance with the needs of society, using scientific and rational teaching methods to improve the quality of teaching, and thus cultivate clothing and apparel design innovation talents.
\end{abstract}

\section{Introduction}

With continuous development of times, the boundary between different countries also become more and more blurred, the internationalization process is accelerating. Clothing and apparel design is a industry without restrictions by countries, while if China's clothing and apparel designers want to cut a figure in the international community, they must have the ability to innovate. However, there is a series of problems in the cultivation of innovative talents of clothing and apparel design, so it is of great significance to explore this direction.

\section{Innovation Talent Training Mode of Clothing and apparel Design Specialty}

If you want to cultivate innovative talents, first of all, you need to develop training objectives, in accordance with the objectives to develop a sound curriculum system and teaching content, to develop scientific and reasonable assessment methods, only in this way can we be able to cultivate innovative talents. For the clothing and apparel design specialty, its biggest feature is that the application is very strong, so if you want to cultivate a number of innovative talents in clothing and apparel design field, should fully take the needs of China's enterprises and social needs into account, need to improve the talent training model in accordance with the current social development and changes, so that the dynamic management of personnel training mode can be achieved. In addition, clothing and apparel design is not subject to national restrictions, therefor, in the process of cultivating innovative talents, we should also introduce international demand.

\section{The Existing Problems of Clothing and Apparel Design Specialty Innovation Talent Training Mode}

Deviation with Market Demand. For colleges, no matter what aspects of personnel training, they should be closely around the market demands. After all, the talents cultivated in colleges are ultimately needed to put into the community, if there is a difference with social needs, it will not help them find suitable place to apply their talents, such talents will be abandoned. However, at this stage, the cultivation of clothing and apparel design specialty innovation talents in China's colleges has a deviation with market demand. At present, the requirements of community to clothing and clothing design talent are obvious, that is, they not only need to master the solid theoretical knowledge, but also should have other aspects of knowledge, in other words, they should have a wealth of comprehensive knowledge, and they should be able to integrate these knowledge systems into the clothing and apparel design. 
At present, when China's colleges cultivate clothing and apparel design specialty innovation talents, more attention are payed to the specialty knowledge of the teaching, so that despite of the students mastering a large number of clothing and apparel design knowledge, but they can not design very good work, unable to deal with some of the practical problems encountered in the design process. With the continuous improvement of people's living standards, the requirements for clothing and apparel are constantly changing, coupled with the growing personalized demand, which put forward higher requirements on the clothing and apparel designers. In China's job market, clothing and apparel design talent is very short, but for the college clothing and apparel design graduates, they are facing the bad situation that graduation is unemployed, in the final analysis, There is a deviation between college personnel training and market demand, resulting in cultivated personnel can not meet the market requirements.

Appreciate the Theory but Neglect the Practice. In fact, not only for clothing and apparel design, many specialties in our country have the similar problem, that is, pay attention to the transfer of theoretical knowledge, and neglect cultivation of practical ability, resulting in training a number of talents who have empty solid theory but do not understand the application. In the clothing and apparel design specialty training, they will start a series of related courses so that the students can master a lot of specialty knowledge. But with regard to the practice of links, it is relatively weak, while it will not be able to cultivate the specialty students with innovation ability without practical operation, after all, clothing and apparel design is a specialty with very application. The reasons why China's colleges appreciate theory but neglect the practice in the specialty talent training mainly include the following three aspects.

First of all, this is closely related to the teaching mode of our country. In most colleges of China, teaching mode applied to is relatively simple, that is to say, almost teaching is completed through classroom, rarely involved in the experimental part. Second, classroom teaching is curing. Regardless of which university in the clothing and apparel design specialty training, they will set the teaching objectives, teaching content and teaching plan, which shows the space that teachers can freely play is very limited, and in order to catch up with the teaching plan, they often do not have too much time and energy to teach students by some practical cases. Moreover, even if the teacher teach practical cases in the classroom for students, but often use the past case, to explain the advantages and disadvantages of the case, which is not conducive to cultivating students' innovative ability, can not make them obtain innovative thinking. Finally, the assessment model is lagging behind. When the course of the specialty students has been finished, teachers will check their learning effectiveness through the examination, and the examination often use paper printed papers, and the examination contents include a number of specialty terms, short answer questions, etc., in order to achieve good grades, students have to remember the contents in the book, even if they don't understand the content but they can remember them to get high marks. This backward assessment model will only train a group of students who understand the theory and don't know how to use it.

\section{Imperfect Course System}

If you want to cultivate clothing and apparel design specialty and innovative talents, there must be a perfect curriculum system, only in this way can we be able to conduct a series of courses in an orderly manner. But in many colleges of China, clothing and apparel design specialty curriculum system is not perfect, there are still some unreasonable place. First of all, in the curriculum system, the proportion of theoretical courses is very large; Secondly, some specialty courses overlap with each other, resulting in students wasting unnecessary time; Finally, some courses have been gradually eliminated by the community, but in some colleges they still appear in the compulsory or elective ranks, leading students to learn something do not meet the current needs of knowledge. 


\section{The Countermeasures for Improving the Innovation Talent Training Mode of Clothing and Apparel Design Specialty}

Change the Educational Philosophy. From the historical point of view, the core idea of education in China is to impart knowledge. Even in modern times, some schools are still upholding this principle, which makes the teacher be the main body of the classroom, the book and their own experience of teachers are imparted to all students without difference. Innovative talent training needs to develop students' innovative thinking and innovation ability, which requires to respect the personality of students, when students put forward some "whimsical" issues, they should be encouraged. But in college clothing and apparel design, teachers are also using classroom teaching methods to impart knowledge to students, teachers taught in the stage of classroom, and students take a note, and some classes do not give students the time to ask questions, so the students can not put forwards doubt, without doubt, they can not make a progress and innovation based on the predecessors. To this end, clothing and apparel design specialty teachers should change the traditional educational philosophy, they should not only focus on lectures, but also should strengthen communication with students in the classroom.

In addition, teachers should combine with the characteristics of the specialty teaching timely. For the students in clothing and apparel design specialty, they are required to have a certain painting skills, for which the specialty opened a course of art. In the art class, teachers often teach them from the perspective of art, independent with the clothing and apparel design, not the combining the specialty characteristics. This is not conducive to students to form a design concept, can not cultivate innovative thinking and innovation ability of students in the design.

Focus on the Construction of Teachers Team. Clothing and apparel design specialty training talents need to rely on teachers to complete, which requires teachers must have a certain degree of innovative thinking and innovation ability, but also have the ability to develop students' innovation ability. It can be said that the requirements of teachers is very high, most of college clothing and apparel design specialty teachers can not meet this requirement, for which colleges and universities should pay attention to the construction of teachers team to enhance teachers' innovative thinking and innovation ability.

First, cultivate teachers' ability to innovate. If you want to cultivate teachers' innovation, they can be accomplished from the following four aspects: First, change the concept of teachers, make them have advanced concepts, thinking more flexible, only in this way can they be able to have the ability to innovate. Second, encourage teachers to teach by combining the cases in current clothing and apparel design, schools and relevant departments can develop the overall objectives of teaching and teaching content, leaving the teacher full of their own space, so that they can introduce new technologies and new methods of the current field into the classroom. Once again, strengthen the exchange of institutions. By strengthening the exchange of institutions, teachers can learn from each other, through mutual discussion they can find a better way to teach. Finally, they should insist on learning the latest specialty knowledge, so as to avoid the aging of their knowledge structure.

Second, the training of "double teacher" teachers. The so-called "double teacher" refers to teachers who have both solid theoretical and practical skills. Colleges should focus on cultivating this type of teacher so that they can introduce more practical examples while conducting theoretical lectures. Besides, they be able to guide students in the practical class.

Perfect Teaching Methods. If you want to cultivate innovative talents, you must have a scientific and rational teaching methods. First, change the previous teaching mode. Teachers should not teach on the podium, but leave the students with plenty of time to discuss. To this end, teachers can introduce a panel discussion in the classroom. After the discussion is completed, the representative of the group explain the point of view, teachers should encourage students to question the contents of the book. Second, improve the assessment methods. In the clothing and apparel design courses, some courses are purely theoretical, then it can be assessed by the form of papers. But some courses are theory plus practice or pure practice, for the former, the assessment can be divided into two parts, the daily practice scores plus the final test scores. As for the curriculum assessment of pure practice, the final results can be replaced by the daily scores 
completely.

Improve the Curriculum System. First, increase the proportion of practical courses. A design theme can be set by the teacher for practical courses, and then the students carry out design, after that, the teacher mark the design, the final total score is recorded in accordance with the average score. Second, focus on the content of the course overlap. For those parts of the course that overlap, if there is a specialty course, then there is no need to teach the second time, but if there is overlap in the content of the elective course, teachers still need to teach them again. Finally, develop hidden lessons. The so-called hidden curriculum can be some school activities, such as the design game, or the transformation of clothing and so on. For the students who has excellent performance can get credit as encouragement.

Strengthen School-Enterprise Cooperation. In terms of Clothing and apparel design specialty, application is very strong, so if you want to cultivate innovative talents, you can not ignore the practice. If you want to practice, in addition to the practical courses set up by the school, but also through cooperating with some enterprises to provide students with the stage of development, so that it can really understand the needs of the current society, and truly apply their knowledge. Colleges can be involved in clothing and apparel design specialty business cooperation, in the holidays, the students can be arranged to visit and practice. In addition, colleges should also encourage students to receive orders through the website, such as pig ring network where many customers who have clothing and apparel design demands, if we can design products to meet customer needs, but also access to funds, which is conducive to improving students' enthusiasm to participate in the activity.

\section{Conclusion}

In summary, with continuous development of the era, people's clothing and apparel needs are constantly developing, and personalized demand become more and more obvious. In this context, the clothing and apparel design students are put forward higher requirements, especially the higher demand to their innovative ability. However, it is found that there are some problems in the training mode of innovative talents in the design of clothing and apparel in colleges of our country, which is characterized by deviations from market demand, appreciate theory but neglect practice, and imperfect curriculum system. The existence of these problems makes the clothing and apparel design students can only master some theoretical knowledge, but do not understand the practical application, naturally can not obtain innovation through the actual operation. To this end, China's colleges innovative talent in the cultivation of clothing and apparel specialty should change the educational philosophy, pay attention to the construction of teachers, improve teaching methods and curriculum system, strengthen school-enterprise cooperation. It is expected that China's colleges will be able to cultivate more innovative talents in the design of clothing and apparel, inject new vitality into China's clothing and apparel design field, promote the development of China's clothing and apparel design, and expand on the international influence on the basis of satisfying the needs of Chinese people.

\section{References}

[1] Zhang Yi. Clothing and apparel design specialty talent training model reform and innovation-taking Liaoning Institute of Media as an example [J]. Art Education, 2016, (11): 188-189.

[2] Huang Jiaxi. Thinking of school-enterprise cooperation personnel training mode in clothing and apparel design specialty [J] .Technology and Education (late), 2016, (09): 78-79.

[3] Liu Qiong, Cheng Xuemin. Thinking of clothing and apparel design specialty innovation talent training mode in new era [J]. Technology and Education (Mid-period), 2016, (07): 67-68.

[4] Zhang Weihua, Yu Weihua. Research on the training mode of apparel application talents based on product line-Taking clothing and apparel design of Hubei Institute of Technology as an example [J]. Journal of Hubei Institute of Technology (Humanities and Social Sciences), 2016, 
(02): 80-82.

[5] Li Deyi. Clothing design specialty talent training mode reform and practice in vocational colleges [J]. Textile and garment education, 2015, (01): 18-23.

[6] Wang Hong. Research and practice of cultivating innovative talents in higher vocational colleges-Taking apparel design specialty as an example [J]. Design, 2014, (11): 191-192.

[7] Li Guangsong. Research on clothing and apparel design specialty innovation talent training model [J]. Shandong Textile Economy, 2014, (03): $20+26$. 